\title{
Effect of Thermal Restraint on Column Behaviour in a Frame
}

\author{
Y. C. WANG and D. B. MOORE \\ Building Research Establishment \\ Garston, Watford WD2 7JR, UK
}

\begin{abstract}
During a fire, a lightly loaded column in a frame may fail due to the additional compressive force generated in the column if its free thermal expansion is restrained. Using the finite element method, a computer program has been developed to analyse the behaviour of steel structures under fire conditions. This program is used to conduct a parametric study to assess the behaviour of a column restrained by the rest of the structural system in a frame. A simple method is proposed to quantify this effect. Additional axial force in the column from both the computer analysis and the simple method are compared and close correlation is obtained. A case study is performed on a restrained column in a real fire. Observation of the failure temperature after fire confirms the applicability of the simple method. It is concluded that column thermal restraint should be taken into account when carrying out fire resistant design for columns. The proposed simple method is capable of predicting this response.
\end{abstract}

KEYWORDS steel frame, column, thermal expansion, axial restraint, fire

\section{INTRODUCTION}

The traditional means of assessing the fire resistance of structural steel load bearing members (e.g. beams, columns) is based on standard furnace fire tests [1]. In this method, a test sample resembling the structural load bearing member in its intended position under its design load is exposed to a standard time-temperature fire exposure.

The many shortcomings associated with this method (e.g. cost, time, limited number of structural forms that can be tested, size and loading conditions) have resulted in a shift from furnace tests towards a more flexible analytical approach. In such a method, the inherent fire resistance of a load bearing member is determined from its temperature dependent material properties and loading conditions. The United Kingdom and European Community structural steel, fire resistant design standards $[2,3]$ reflect this advance and allow the fire resistance of various types of load bearing member to be determined by calculation.

Both standards use the load ratio to calculate the critical temperature of a loadbearing member. This is the ratio of the applied load to the load carrying capacity of the member at ambient temperature. The critical temperature of the member is the temperature at which its load carrying capacity is equal to the applied load. Different values of temperature are given for different types of structural members e.g. columns, beams with concrete slabs on top, bare beams at various load 
ratios. The essential problem is therefore to determine the load ratio (i.e. internal stress resultants in the member). This does not present any difficulty if the distribution of forces in the structure remains unchanged during fire e.g. the structure is statically determinate. However, for a realistic structure, the force distribution will change under fire conditions as members lose their stiffness. Continuity effects may restraint the thermal expansion of those members within the fire compartment and this effect can also change the distribution of forces in the structure. This restraint often results in an additional compressive force in columns therefore increases its load ratio and reduces its fire resistance.

This paper addresses the effect of restrained thermal expansion. A computer program developed by the authors for the analysis of steel frames under fire conditions is briefly described followed by a limited parametric study to investigate the effect of restraining a column's thermal expansion in a model frame. A simple equation is then suggested to quantify this effect and results from this equation are compared with numerical results from the computer program. The applicability of this equation is then checked by calculating the failure temperature of a lightly loaded column in a fire.

\section{ANALYSIS OF STEEL FRAMES AT ELEVATED TEMPERATURE}

In this analysis, the total Lagrangian approach and the principle of virtual work are employed to formulate the basic equations. These equations are then linearized to express unknown quantities at time $t+\Delta t$ as the sum of known ones at time $t$ and their increments during the time interval $\Delta t$. The following expression is obtained [4]

$\int_{v} \mathrm{Ce} \delta e d V+\int_{v} \mathrm{~S} \delta \eta \mathrm{dV}=\delta^{1+\Delta} \mathrm{W}_{\mathrm{ext}}-\int_{\mathrm{v}}{ }^{\mathrm{S}} \mathrm{S} \delta \mathrm{edV}$

in which $\mathrm{C}$ is the constitutive tensor; $\mathrm{e}$ and $\eta$ are linear and non-linear parts of the Green-Lagrange strain tensor; ' $S$ the known stress tensor at time $t$ and $\delta^{t+\Delta t} W_{\text {ext }}$ the virtual work done by external forces. The integration is over the undeformed configuration.

The frame is then discretized using line elements to represent beam-column members. Shape functions are used to represent the displacement field as functions of nodal displacements. In this analysis, each node has 6 degrees of freedom (axial, bending about two directions and twist). Linear functions are used for axial and torsional displacements and cubic functions are used for bending.

The two important features in analysing steel frames at elevated temperature are thermal strain and the temperature dependent constitutive relationship of steel. In this study, thermal expansion and creep strain are included. For the constitutive relationship, tabulated stress-strain values at various temperature data from British Steel [5] tests and two mathematical models are used.

Due to the nonlinear nature of the problem, an iterative method is used. In this study, the Newton-Raphson method with load/temperature increment is used to find the equilibrium at various load/temperature levels. The program is terminated if the stiffness matrix becomes nonpositive.

A computer program is developed according to this method [6]. It can be used to perform ultimate strength analysis at ambient temperature and failure temperature analysis under fire 
conditions. Its features include flexible beam-column connections, second order effects, nonlinear material properties, non-uniform cross-sectional temperature distributions as well as initial deflections. It is developed for three dimensional frame analysis, although verification is carried out for plane frames due to the limited availability of test results.

\section{VERIFICATION}

The computer program has been used to simulate various standard fire tests on beams and columns as well as a limited number of frame fire tests [6]. The following results are used to illustrate the accuracy and capacity of the program.

1. Rubert and Schaumann [7] tested a series of 3 types of model frames. Type EHR had two members perpendicular to each other rigidly connected at the joint and fixed at supports; Type EGR was a one bay one storey frame rigidly jointed at the connection and pinned at the bases. All members of both types were heated. Type ZSR frame was a two bay one storey frame simply supported with rigid connections. Only one bay was heated and the two remaining members were cold. In all cases, heating was uniform. These frames were typically $1220 \mathrm{~mm}$ in span and 1170 $\mathrm{mm}$ in height. These frames were analysed using the computer program. Comparison of analytical results against tests results for failure temperature are listed in table 1. A satisfactory correlation between analysis and test is generally observed and the results predicted by the program generally lower than the test results.

TABLE 1. Comparison of critical temperatures for small scale steel frames

\begin{tabular}{|l|l|l|}
\hline Frame Type & Test result [7] & Present analysis \\
\hline EHR 1 & 600 & 645 \\
\hline EHR2 & 530 & 565 \\
\hline EHR3 & 475 & 480 \\
\hline EHR4 & 562 & 585 \\
\hline EHR5 & 460 & 430 \\
\hline EGR1 & 515 & 450 \\
\hline EGR2 & 612 & 595 \\
\hline EGR3 & 388 & 380 \\
\hline EGR4 & 424 & 410 \\
\hline EGR5 & 335 & 310 \\
\hline EGR6 & 350 & 310 \\
\hline EGR7 & 454 & 405 \\
\hline EGR8 & 464 & 405 \\
\hline ZSR1 & 547 & 485 \\
\hline ZSR2 & 479 & 440 \\
\hline ZSR3 & 574 & 580 \\
\hline
\end{tabular}


2. A full scale portal frame was tested in a real fire by the British Steel Corporation in collaboration with the Building Research Establishment, UK [8]. Wood cribs were used to simulate the real fire. The frame was assumed to be rigidly connected and non-sway. This test frame was analysed using the authors computer program. The deflection at the centre of the beam is compared with the test result as depicted in figure 1. It shows that the predicted curve follows the test curve closely until failure of the frame is approached. The fire resistance time is about $12 \%$ lower, but the difference in terms of temperature is much smaller being $2 \%, 6 \%$ and $0.3 \%$ respectively in the lower flange, upper flange and web mid-height of the I-beam section. This is due to the much slower increase in temperature at the end of fire attack.

No specific test results with respect to the influence of axial restraint were available for comparison. However, it is believed from the above comparisons for steel frames in fire conditions that the computer program can be used to study the effect of axial restraint.

\section{GENERAL OBSERVATION OF THERMAL RESTRAINT ON A COLUMN IN A FRAME}

If the rest of the frame is assumed to be an axial restraint on the column (cf figure 2), the additional axial load generated in the column may be expressed as:

$\Delta \mathrm{P}=\alpha_{\mathrm{f}}\left(1+\alpha_{\mathrm{t}}\right) \mathrm{K}_{\mathrm{c}}\left(\Delta \epsilon_{\mathrm{th}}-\Delta \epsilon_{\mathrm{mec}}\right) \mathrm{L}_{\mathrm{c}}$

in which $\Delta P$ is the additional compressive load generated in the column; $\alpha_{t}=k_{s} / k_{c}$, where $k_{s}$ and $\mathrm{k}_{\mathrm{c}}$ are respectively the stiffnesses of the rest of the frame acting as an axial spring and the column; $\Delta \epsilon_{\text {th }}$ and $\Delta \epsilon_{\text {mec }}$ are the free thermal strain increment due to the temperature rise and the mechanical strain difference under constant stress due to material property change and $\mathrm{L}_{\mathrm{c}}$ is the column length. A similar equation was used by Pettersson et al [9] who evaluated the column axial stiffness using the secant modulus over the entire temperature range.

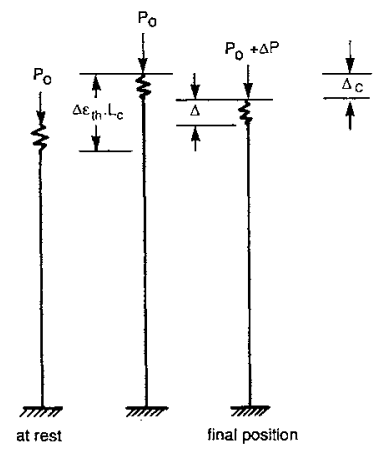

$$
\begin{aligned}
\Delta C & =\frac{P_{0}}{k_{(1)}}-\frac{P_{0}}{K_{\infty}}+\frac{\Delta P}{K_{c}(t)} \\
& =\Delta \varepsilon_{\text {mec }} \cdot L_{c}+\frac{\Delta P}{K_{c}(t)} \\
\Delta & =\Delta E_{E_{b}} \cdot L_{c}-\Delta_{c} \\
& =\frac{\Delta P}{K_{s}}
\end{aligned}
$$

Figure 2. Column expansion in fire 


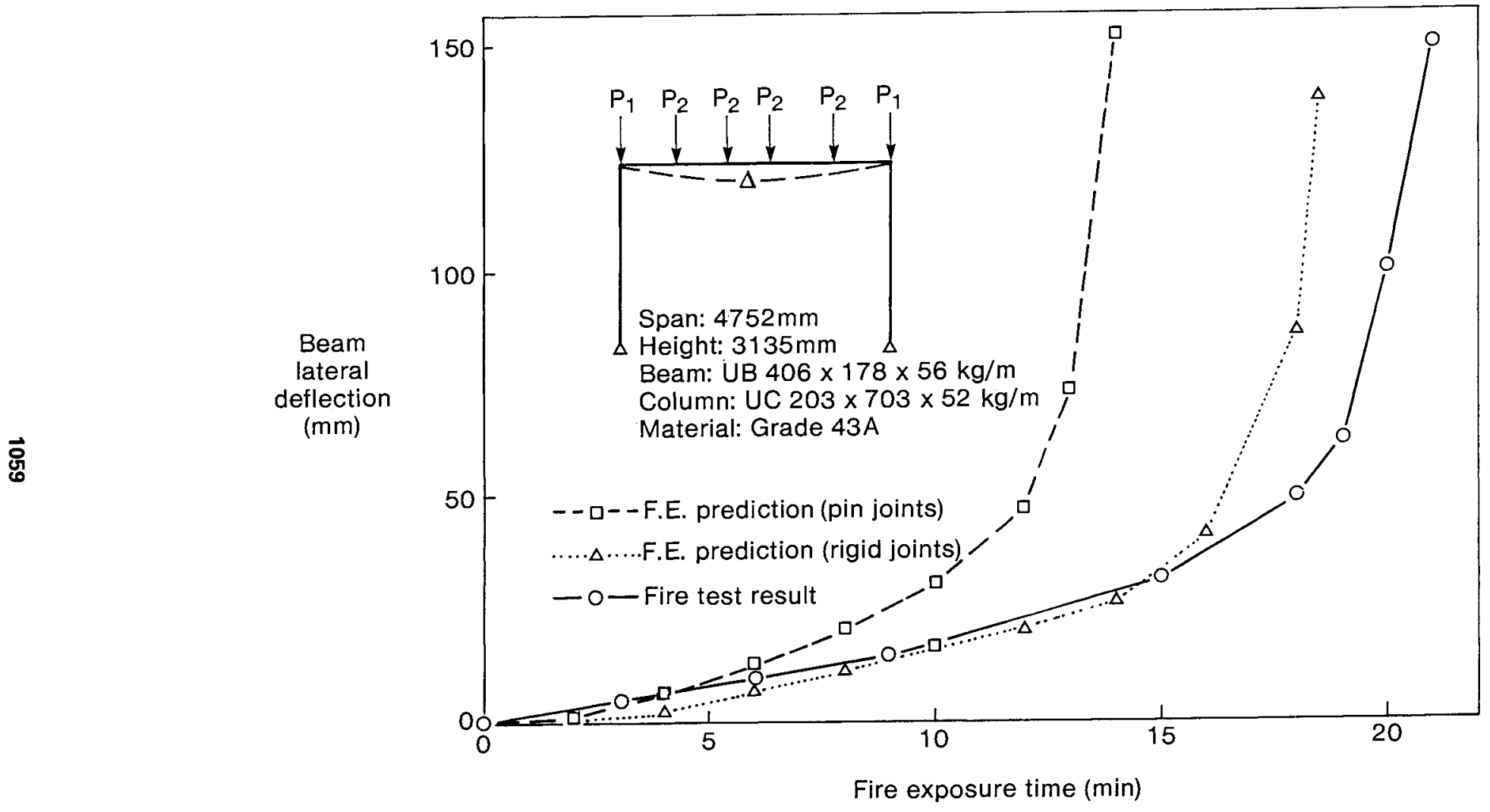

Figure 1. Comparison for full scale steel frame in natural fire 
Equation (2) implies that if the free thermal strain increment is greater than the mechanical strain difference, an additional compressive force is generated in the column. This is generally true at the initial stage of fire exposure or for columns of high slenderness ratios since the mechanical strain difference is very small due to the negligible change in material properties and/or the low applied stress. However, for a column of low slenderness ratio at high temperature, $\Delta \epsilon_{\text {moc }}$ may be higher than $\Delta \epsilon_{\text {th }}$ and as a result, an additional tensile force is generated in the column, reducing its compressive stress. Apparently the higher the initially applied load, the lower the required temperature at which the column compressive load reduces. The magnitude of the additional axial force in the column depends also on the ratio of the restraining stiffness to the column axial stiffness. A higher ratio gives larger additional axial force.

An extreme application of equation (2) is a column with a heavy structure on top $\left.\left(\mathrm{k}_{\mathrm{s}}\right) \mathrm{k}_{\mathrm{c}}\right)$ and no externally applied load. In this case, the column length does not change and all the free thermal strain is converted to generating mechanical strain and stress. The additional compressive force in the column is:

$P_{\mathrm{d}_{1}}=A_{\mathrm{c}} \times \sigma_{\mathrm{th}}$

in which $\sigma_{\text {th }}$ is the stress corresponding to total free thermal strain $\epsilon_{\text {th }}$ and $A_{c}$ the column cross-section area.

The load carrying capacity of the column is the lesser of its squash load and buckling load at elevated temperature. From the steel stress-strain curves at elevated temperature, the value of $\sigma_{\text {th }}$ at temperature up to $800^{\circ} \mathrm{C}\left(\epsilon_{\text {th }} \simeq 0.01\right)$ is still less than its ultimate stress. Therefore, the loss of the column's ability to sustain further load is due to the buckling load of the column being exceeded. The buckling load is controlled by the tangent modulus at elevated temperature. The condition for the column to fail at thermally induced load may be expressed as:

$\mathrm{E}_{\mathrm{e}}<\mathrm{E}_{\mathrm{ren}}=\lambda^{2} / \pi^{2} \times \sigma_{\mathrm{th}}$

where $\lambda$ is the column slenderness ratio and $E_{\mathrm{e}}$ the tangent modulus of the steel at elevated temperature under stress $\sigma_{\text {th }}$.

For slender columns, $E_{\text {req }}$ is large. This implies that the failure condition is easily satisfied. Therefore, the thermal restraint is much more detrimental to slender columns.

\section{PARAMETRIC STUDY}

To verify the above theoretical deductions, a limited parametrical study is carried out on a non-sway one storey by two bay steel plane frame as shown in figure 3 . It has relatively strong beams $\left(610 \times 229 \mathrm{UB} 101, \mathrm{~L}_{\mathrm{c}}=6000 \mathrm{~mm}\right)$ and weak columns $(254 \times 254 \mathrm{UC} 89)$. Columns are Grade $50 \mathrm{~B}$ steel $\left(\sigma_{\mathrm{y}}=355 \mathrm{~N} / \mathrm{mm}^{2}\right.$ and $\left.\mathrm{E}_{0}=200,000 \mathrm{~N} / \mathrm{mm}^{2}\right)$. Parameters are column effective slenderness $(\lambda=20,60,100,200)$, beam stiffness $\left(E_{o b} / E_{0 c}, \sigma_{y b} / \sigma_{y c}=0.5,1,2,10,20\right)$ and applied load $\left(P /\left(p_{c} A_{c}\right)=\right.$ $0.0,0.4,0.6$ and 0.8 ). Only the central column is heated uniformly. Other members of the frame remain cold.

Failure temperatures for the heated column are obtained from the computer program. They are 


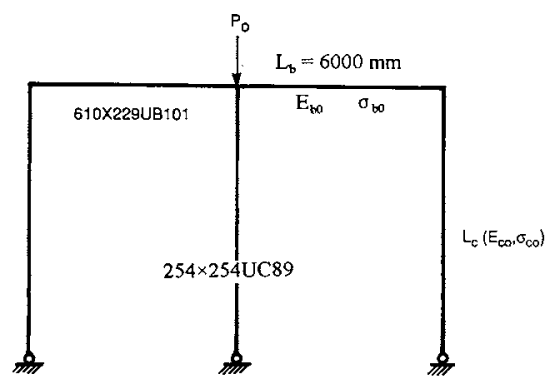

Figure 3. Model frame

plotted in figures $4 \mathrm{a}-4 \mathrm{~d}$. As predicted, the failure temperature of the column in the frame with stiffer beams (implying a higher system restraining stiffness) is generally lower. However, the reduction rate in the column failure temperature decreases with increase in the applied load, confirming the effect of $\Delta \epsilon_{\text {mec }}$ in equation (2). Moreover for a loaded column of low slenderness ratio $(\lambda=20)$, a slight increase in its failure temperature is obtained. This is in agreement with the conclusion drawn above that the large mechanical strain due to the high applied stress in the column reduces the effect of thermal expansion and may pull down on the rest of the building system, resulting in a reduction in the column axial compressive load and an increase in its failure temperature. However, this beneficial effect is small. The effect of the increased axial load in the column due to the restrained thermal expansion is more detrimental for slender columns and columns with a small axial load.

The entire parametric study was repeated for Grade $43 \mathrm{~A}$ steel with a yield stress at room temperature of $275 \mathrm{~N} / \mathrm{mm}^{2}$. No difference in column ultimate temperature was observed.

\section{DETERMINATION OF ADDITIONAL AXIAL FORCE IN COLUMN}

Equation (2) expresses the dependence of the additional axial force generated in a column on the tangent stiffness, the stiffness of the structural system and the net change in its strain. In a realistic structure, the axial restraining stiffness from each floor (bending stiffness) is much lower than the axial stiffness of the supporting columns. The structural system stiffness may therefore be obtained as the sum of the stiffness of the floors above the column, assuming equal floor movement. An iteration method has to be employed to calculate the axial force change.

This approximate approach was applied to the fire exposed column of a model frame composed of two storeys of the basic frame in figure 3 with the material properties of the upper storey members magnified to various multiples $\left(S_{R}=0.5,1,2,10,20,100\right)$ of the lower storey to reflect the effect of the different number of floors above. Other parameters were column slenderness (20 and $100)$ and applied load $\left(\mathrm{P}_{0}=0\right.$ and $\left.0.6 \mathrm{p}_{\mathrm{c}} \mathrm{A}_{\mathrm{c}}\right)$.

Similar results were obtained for all cases. Figures $5 \mathrm{a}-5 \mathrm{~d}$ show comparisons between the 'exact' method (computer analysis) and the approximate method (equation (2)) for the column axial load against temperature relationship for $S_{R}=1,10$ and 100 of both column slendernesses and load values. Reasonable agreement is obtained in all cases, confirming the applicability of the approximate method. It is noticed that the most significant discrepancy is for $S_{R}=100$. This is 

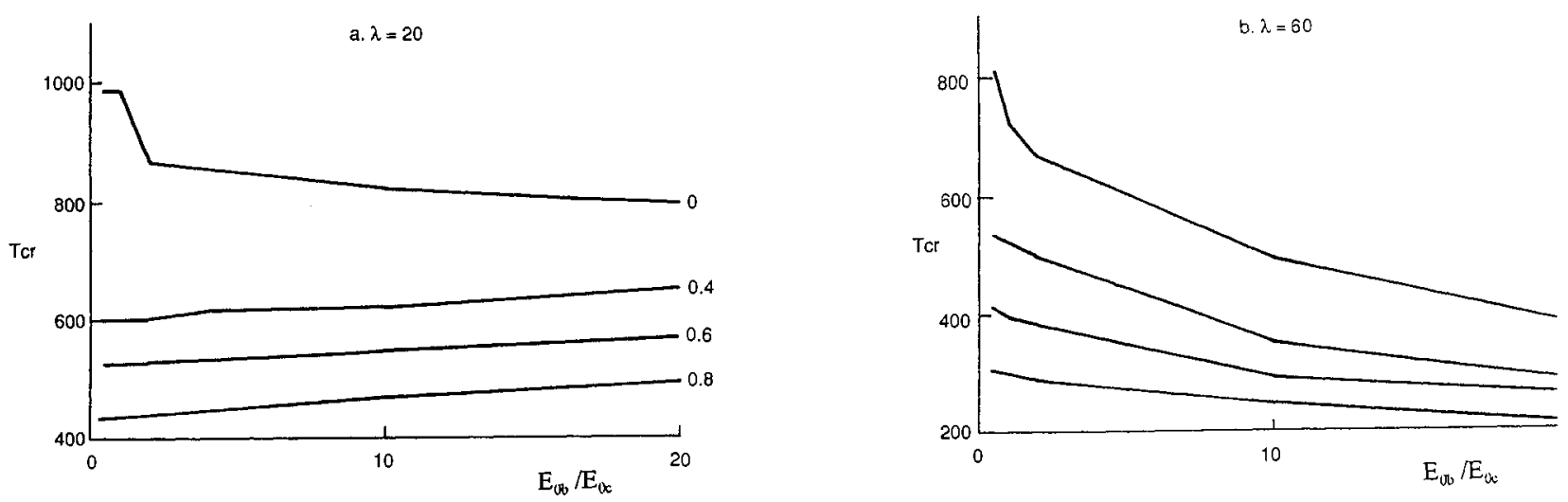

용

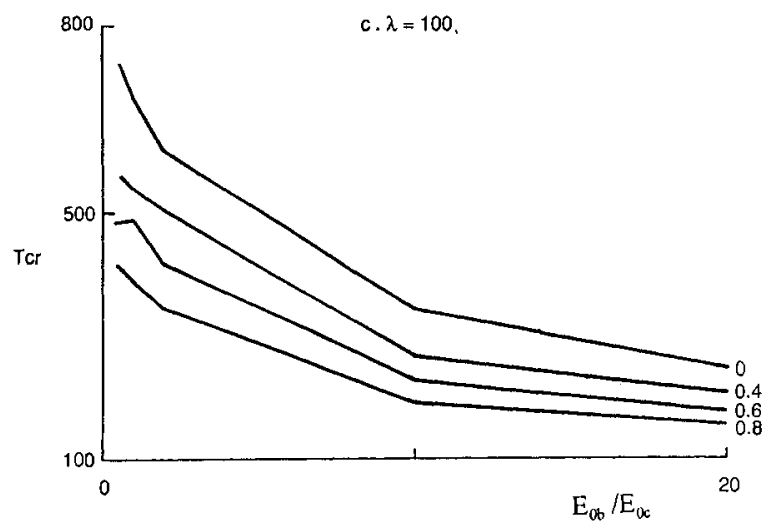

d. $\lambda=200$

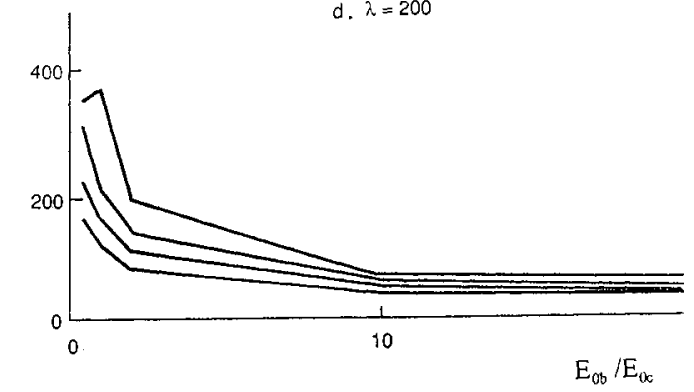

Figure 4. Failure temperature for various columns sienderness $\lambda_{c}$, beam/column stiffness $E_{0 b} / E_{0 c}$ and load ratio 


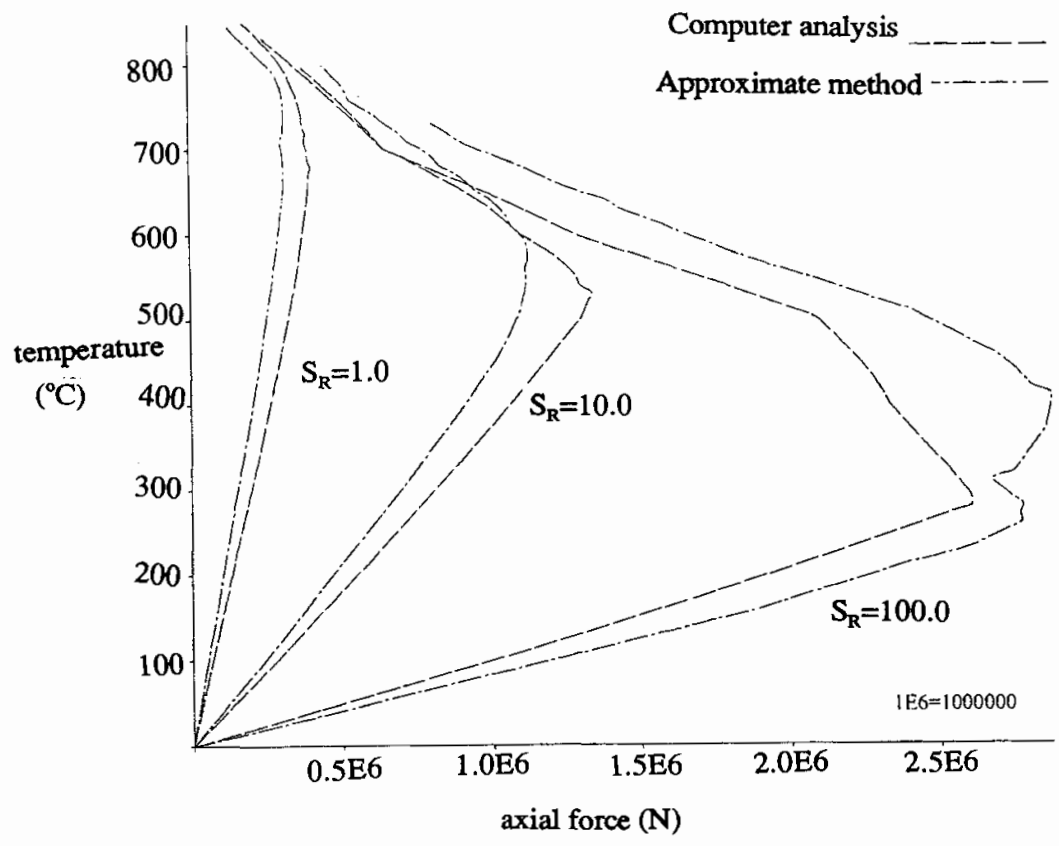

Figure 5a. Axial force - temperature relationship for $\lambda=20$, no load

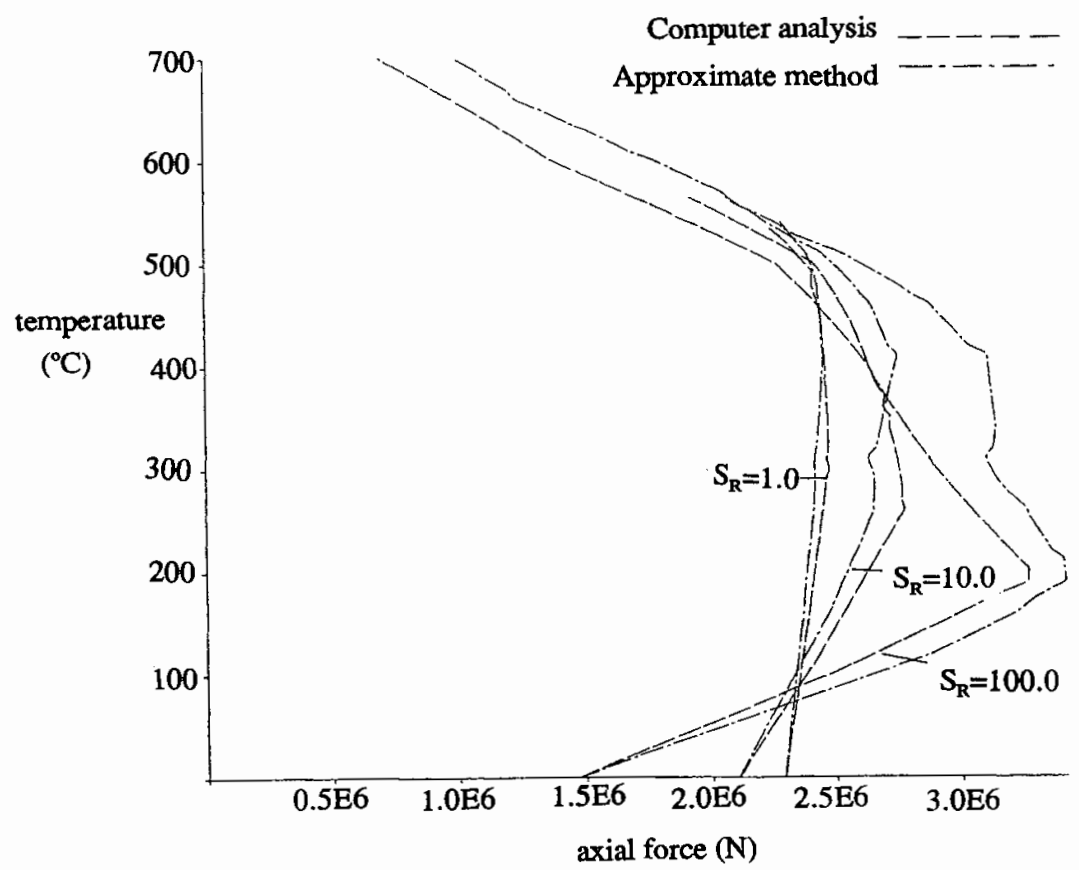

Figure 5b. Axial force - temperature relationship for $\lambda=20$, with load $=0.6 p_{c} A_{c}$ 


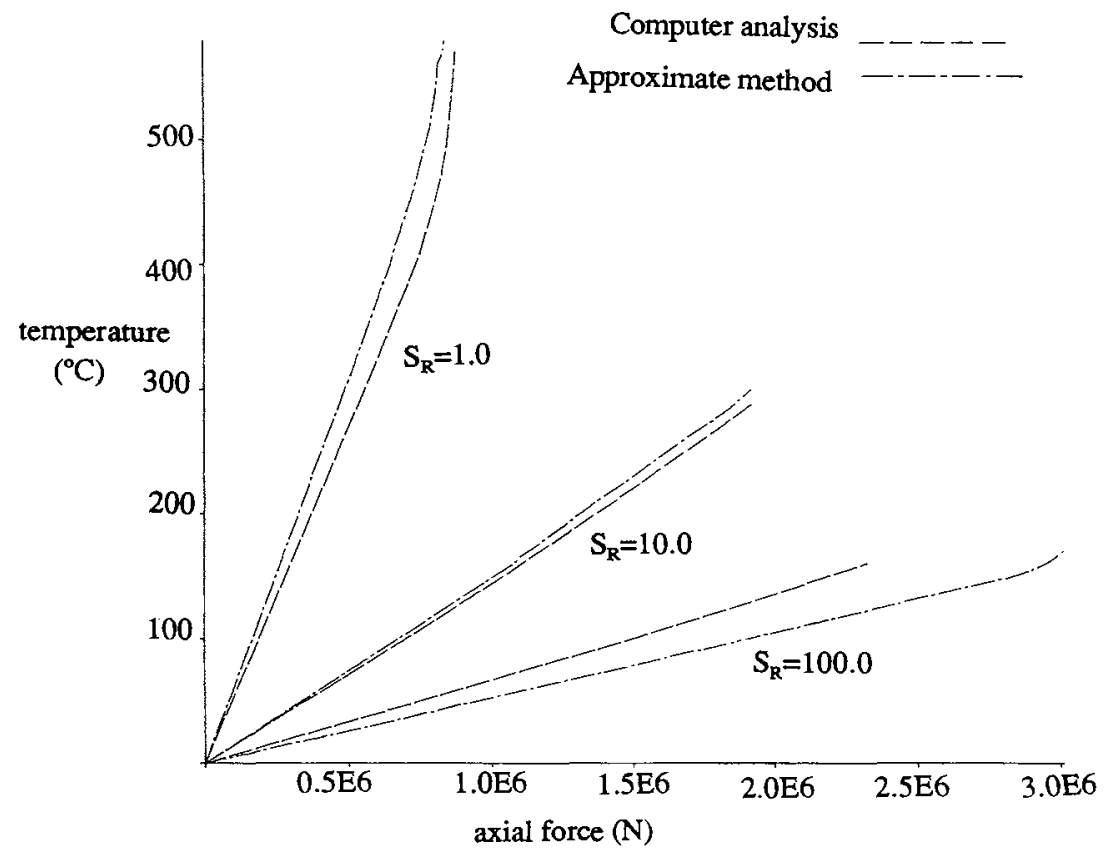

Figure 5c. Axial force - temperature relationship for $\lambda=100$, no load

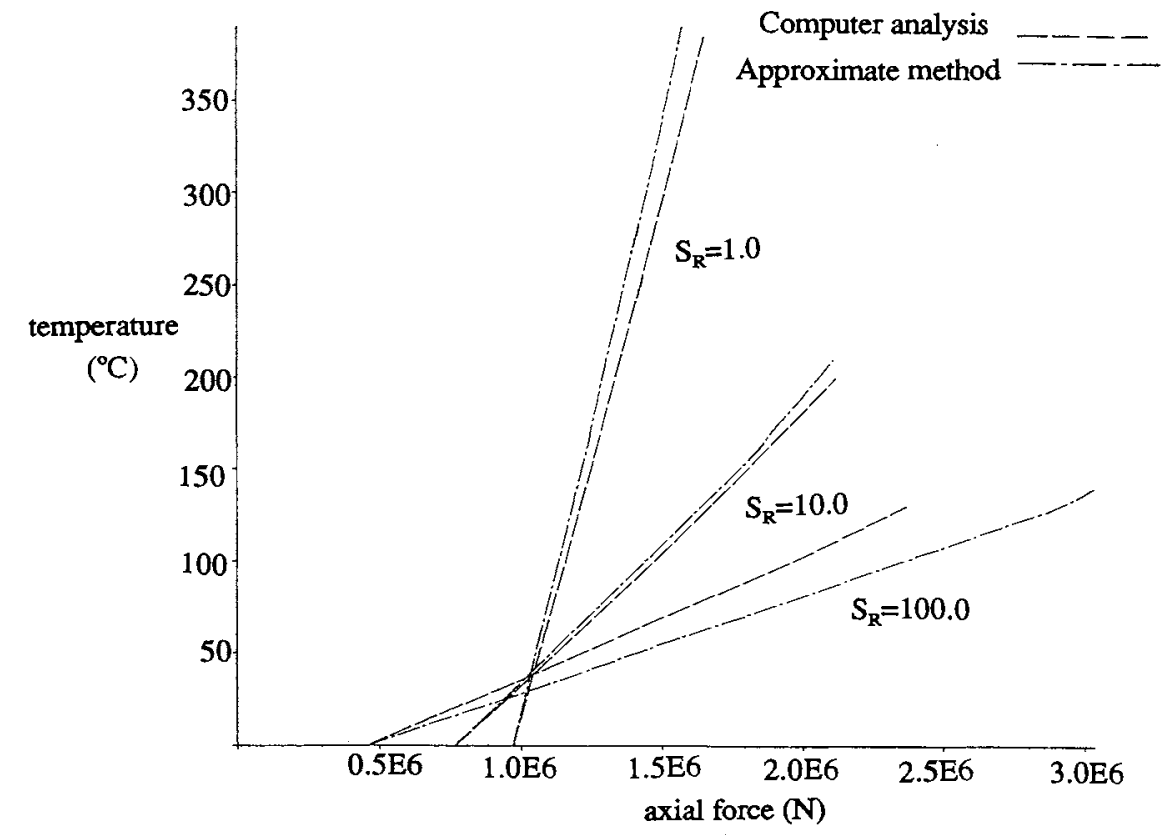

Figure 5d. Axial force - temperature relationship for $\lambda=100$, with load $=0.6 \mathrm{p}_{c} A_{c}$ 
expected since the assumption of equal floor movement is questionable for buildings with a large number of floors.

\section{AN EXAMPLE}

A severe fire occurred during the construction of the Broadgate building complex in London. At this stage in construction the applied load was very small, but some columns were found to have failed. It was suggested that this failure may be due to the axial compression generated in the column from the thermal restraint provided by the rest of the building system. Using the approximate method, the failure temperature of the $\mathrm{C}$-line columns in the Broadgate fire was established. The column was a $356 \times 406 \mathrm{UC} 287\left(\mathrm{~A}_{\mathrm{c}}=36600 \mathrm{~mm}^{2}\right)$ of $4800 \mathrm{~mm}$ in length and the restraining stiffness of the system was between $100 \mathrm{kN} / \mathrm{mm}$ and $1400 \mathrm{kN} / \mathrm{mm}$. The temperature versus load ratio relationship for three values of system stiffness $(100 \mathrm{kN} / \mathrm{mm}, 200 \mathrm{kN} / \mathrm{mm}$ and $500 \mathrm{kN} / \mathrm{mm}$ ) are plotted in figure 6 . The intersection of each curve with the critical temperature-load ratio curve from BS5950 Part 8[2] gives the failure temperature for each system stiffness. Failure temperature values of $640^{\circ} \mathrm{C}, 600^{\circ} \mathrm{C}$ and $500^{\circ} \mathrm{C}$ are obtained respectively. This is in agreement with the failure temperature of about $600^{\circ} \mathrm{C}$ observed from examination of the structure after the fire.

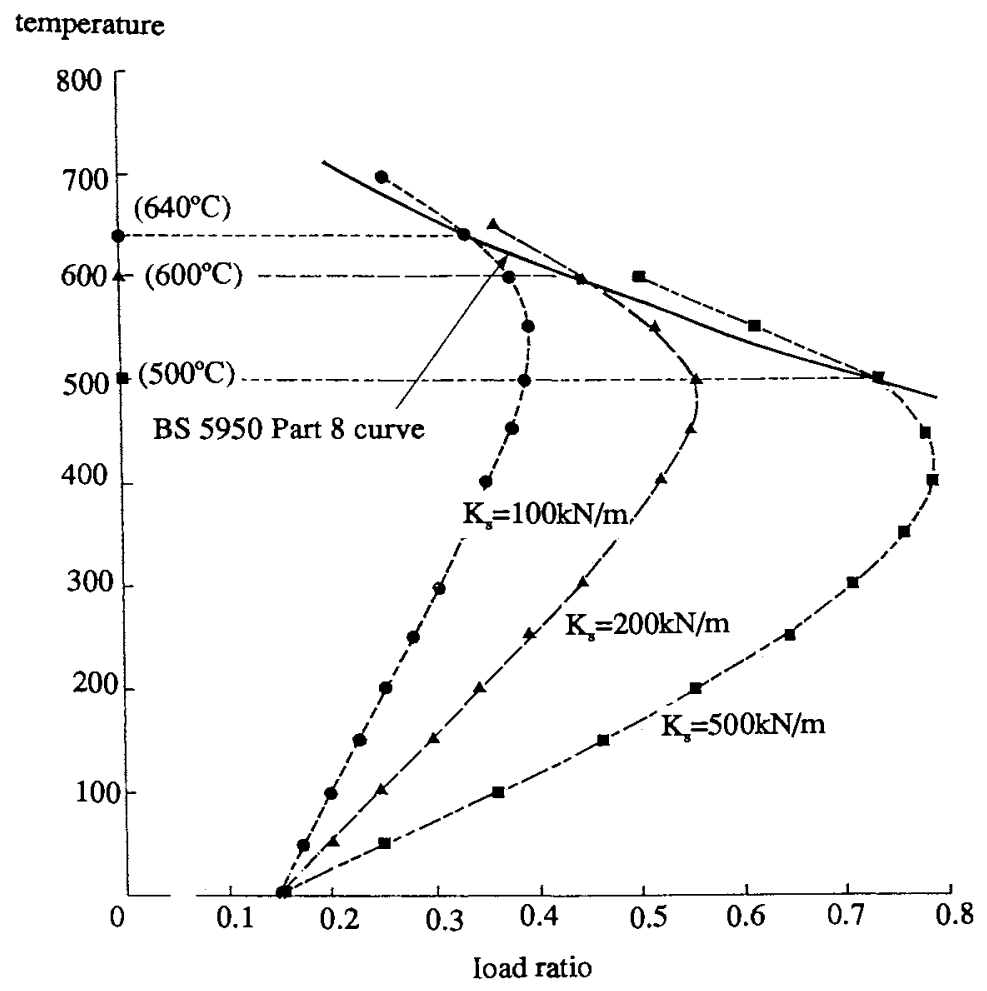

Figure 6. Determination of column failure temperature 


\section{CONCLUSIONS}

A finite element program has been developed to analyse the behaviour of steel frames under the fire conditions. It is used to study the influence of axial restraint on the failure temperature of steel columns. The following conclusion may be drawn:

1: The program is capable of correctly predicting the behaviour of steel frames in fire;

2: The effect of thermal restraint has to be taken into consideration in the fire resistant design of steel columns. This effect generally increases the axial compressive force in the column and is particularly detrimental for slender columns;

3: The magnitude of the additional axial force in a column depends on the column stiffness, the restraining stiffness of the system, the column slenderness and initially applied axial load in the column. This relationship is expressed in equation (2);

4: Comparison of results from this equation with the more exact analysis confirms the applicability of the simplified approach.

\section{REFERENCES}

1. British Standard Institution, BS476: Part 8, Fire Tests on Building Baterials and Structures, Test Methods and Criteria for the Fire Resistance of Elements of Building Construction, British Standards Institution, 1972

2. British Standard Institution, BS5950: The Structural Use of Steelwork in Building. Part 8 Code of Practice for Fire Resistant Design. British Standards Institution, 1990

3. Commission of the European Communities, Eurocode 3 Design of Steel Structures, Part 1.4: Fire Resistance, Draft prENV 1993-1-2, British Standards Institution, 1992

4. Bathe,K.J., Finite Element Procedures in Engineering Analysis, Prentice-Hall, Inc., Eaglewood Cliffs, New Jersey, 1982

5. Kirby,B.R., Recent Development and Application in Structural Fire Engineering Design - A Review, Fire Safety Journal. 11, pp. 141-179, 1986

6. Wang,Y.C. and Lennon, T., A Computer Program for Structural Analysis at Elevated Temperature, Building Research Establishment Client Report CR77/92, 1992

7. Rubert,A and Schaumann,P., Structural Steel and Plane Frame Assemblies under Fire Action, Fire Safety Journal, 10, pp. 173-184, 1986

8. Latham,D.J., Thomson,G., Kirby,B.R. and Wainman,D.E., Second Natural Fire Test on a Loaded Steel Frame at Cardington, RS/RSC/7281/12/86/E. British Steel Corporation, Swinden Laboratories, May 1986

9. Pettersson,O., Magnusson,S.E. and Thor,J., Fire Engineering Design of Steel Structures, Swedish Institute of Steel Construction, Publication 50, Stockholm 1976 